[Agr. Biol. Chem., Vol. 35, No. 10, p. 1625 1627, 1971]

\title{
Pressure Effect on the Reactivation of Neutralized Acid-denatured Taka-amylase A
}

\author{
By Toshiko Kanemitsu and Kinjiro Mryagawa \\ Laboratory of Chemistry, Osaka-Joshigakuen College, Tennoji, Osaka \\ Received January 25, 1971
}

During the course of an investigation of the inactivation and reactivation of Taka-amylase A (Asp. oryzae $\alpha$-amylase, TAA) [EC. 3.2.1.1] by pressure, TAA was found to be inactivated by pressure at above $4000 \mathrm{~kg} / \mathrm{cm}^{2}$, and the recovery of the activity of pressure-inactivated and heat-inactivated TAA was found to be enhanced by pressure up to $3000 \mathrm{~kg} / \mathrm{cm}^{2} .^{1 \sim 5}$ However, the detailed mechanism of the enhancement of the inactivated enzyme by pressure is still unsolved. High pressure more than $4000 \mathrm{~kg} / \mathrm{cm}^{2}$ tends of cause denaturation. On the contrary, moderate pressure up to $3000 \mathrm{~kg} / \mathrm{cm}^{2}$ tends to re-nature the denatured protein. ${ }^{2,51}$ From these results it is assumed that changes in molar volume at the time of inactivation by a pressure of more than 4000 $\mathrm{kg} / \mathrm{cm}^{2}$ and the reactivation processes are both negative. This is a very curious phenomenon. If this is a common phenomenon, moderate pressure will be expected to enhance reactivation of TAA denatured by other various denaturants.

The present study was undertaken to investigate the effect of moderate pressure on reactivation of acid-denatured TAA, since renaturation of acid-denatured TAA has already been studied in detail by Takagi and Toda. ${ }^{61}$

1) K. Miyagawa and K. Suzuki, Arch. Biochem. Biophys., 105, 297 (1964).

2) K. Miyagawa, K. Sannoe and K. Suzuki, ibid., 106,467 (1964).

3) K. Miyagawa, ibid., 110, 381 (1965).

4) K. Miyagawa, ibid., 113, 641 (1966).

5) K. Miyagawa, Agr. Biol. Chem., 31761 (1967).

6) T. Takagi and H. Toda, J. Biochem., 52, 16 (1962).
TAA used in this investigation was crystalyzed according to the method of Akabori et $a l$. " from "Taka-diastase Sankyo" The concentration of TAA was estimated spectrophotometrically, assuming an $E_{1 \mathrm{~cm}}^{1 \%}$ of 22.1 at $278.5 \mathrm{~m} \mu$. Adjustment of $\mathrm{pH}$ was made by adding $1.0 \mathrm{~N}$ hydrochloric acid and $1.0 \mathrm{~N}$ sodium hydroxide under vigorous stirring to avoid a local excess of acid or alkali. Activity was determined at $\mathrm{pH} 5.5$ ( $0.05 \mathrm{M}$ acetate buffer) and at $30^{\circ} \mathrm{G}$ by measuring its dextrinizing power with dinitro-salicylic acid according to the method of Noelting and Bernfeld. ${ }^{8)}$ Soluble starch was used as a substrate. The TAA concentration used for the measurement of the enzymic activity was $2 \times 10^{-4} \%$. The high pressure apparatus and procedure were the same as previously reported by Suzuki. ${ }^{91}$

Figure 1 shows changes in the turbidity of acid-denatured and then neutralized TAA. An unbuffered aqueous solution of TAA $(0.89 \%)$ was acidified to $\mathrm{pH} 1.0$ and stood for $10 \mathrm{~min}$ at $30^{\circ} \mathrm{C}$, then neutralized to $\mathrm{pH} 7.0$ (the following experiments were carried out under the same conditions unless otherwise indicated). Some of the samples were compressed at a pressure of $1500 \mathrm{~kg} / \mathrm{cm}^{3}$ for $20 \mathrm{~min}$. Turbidity was measured at $500 \mathrm{~m} \mu$ with time. Aciddenatured TAA was heavily turbid, but the turbidity was decreased with time when the

7) S. Akabori, T. Ikenaka and B. Hagihara, J. Biochem., 41, 577 (1954).

8) G. Noelting and P. Bernfeld, Helv. Chim. Acta, 31, $286(1948)$.

9) K. Suzuki, Rev. Phys. Chem. Japan, 28, 24 (1958). 


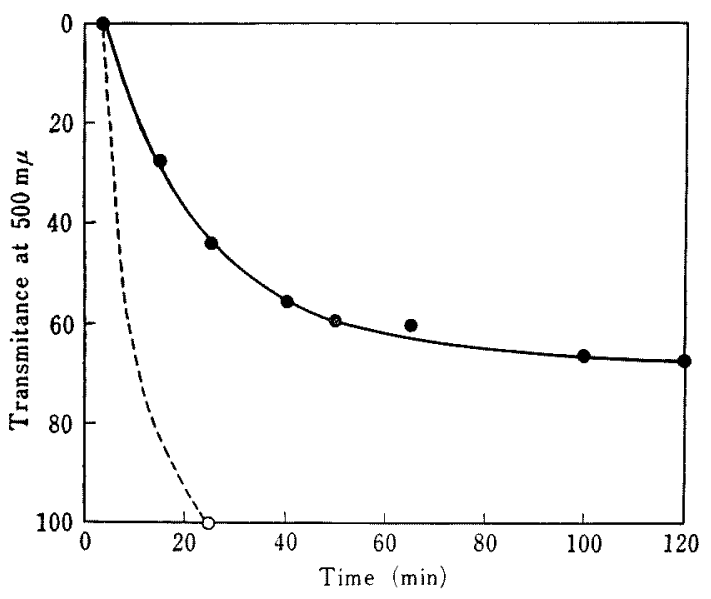

FIG. 1. Changes in Turbidity with Time.

TAA $\left.\left(0.89^{\circ}\right)^{\circ}\right)$ was acidified to $\mathrm{pH} 1.0$, kept for $10 \mathrm{~min}$, and neutralized to $\mathrm{pH} \mathrm{7.0.} \mathrm{Transmittance}$ was measured at $500 \mathrm{~m} \mu$ with time. Dotted line, under a pressure of $1500 \mathrm{~kg} / \mathrm{cm}^{2}$.

sample was neutralized. It did not become transparent under atmospheric pressure, whereas turbid TAA was cleared up by compression, suggesting that disaggregation of coagulated TAA is enhanced by pressure.

The effect of pressure magnitude on the reactivation of neutralized TAA is shown in Fig. 2. A pressure of about $1500 \mathrm{~kg} / \mathrm{cm}^{2}$ was optimum for the recovery. This result is the same as that of the effect of pressure on the reactivation of pressure-inactivated and heatinactivated TAA. ${ }^{2.51}$

Figure 3 shows the time courses of the reactivation of acid-inactivated and then neutralized TAA. After neutralization, some of the samples were kept under atmospheric pressure and the remainders were compressed at $1500 \mathrm{~kg} / \mathrm{cm}^{2}$ for $10,20,45$ and $60 \mathrm{~min}$. After releasing the pressure, activities were measured with time. When compression was applied for different periods, activities at the time of releasing the pressure were almost the same, and the activities gradually increased to reach the same degree. That is, the compression time is almost independent of the reactivation, and the reactivation process by pressure seems to be fast.

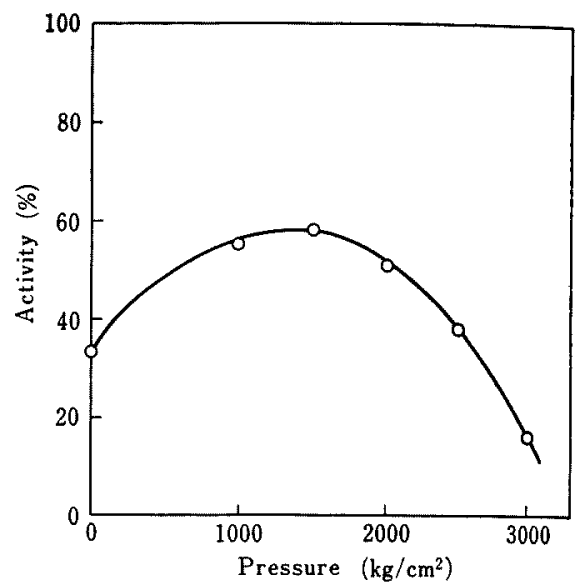

FIg. 2. Effect of Pressure Magnitude on the Reactivation.

TAA $(0.89,6)$ was acidified to $\mathrm{pH} 1.0$, and kept for $10 \mathrm{~min}$, neutralized to $\mathrm{pH} 7.0$, and then compressed under various magnitudes of pressure for $20 \mathrm{~min}$. Activity was measured at $30 \mathrm{~min}$ after releasing the pressure. Temperature: $30^{\circ} \mathrm{C}$.

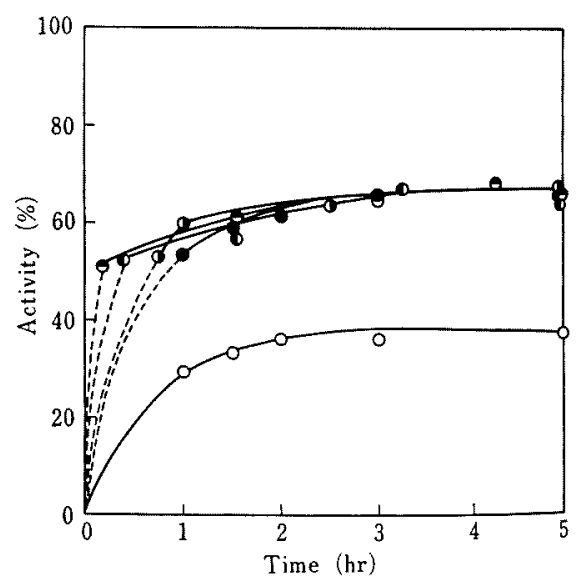

FIG. 3. Time Courses of the Reactivation.

TAA $(0.89 \%)$ was acidified to $\mathrm{pH} 1.0$, kept for $10 \mathrm{~min}$, and neutralized to $\mathrm{pH} 7.0$, and then compressed at $1500 \mathrm{~kg} / \mathrm{cm}^{2}$ for 10 (-), $20(\mathbf{C}-\mathbf{0})$, $45(0-0)$, and $60(-0)$ minutes. $(0-0)$ indicates the time course of the reactivation under atmospheric pressure. Temperature: $30^{\circ} \mathrm{C}$. 
Effect of initial concentrations of TAA on the reactivation was examined. Each concentration of TAA was acidified, and then neutralized. A portion of the sample was compressed at $1500 \mathrm{~kg} / \mathrm{cm}^{2}$ for $60 \mathrm{~min}$ and the remainder was kept under atmospheric pressure. The activity of each sample was measured $2 \mathrm{hr}$ later after releasing the pressure. As shown in Fig. 4, concentrations of 0.01 to $0.1 \%$

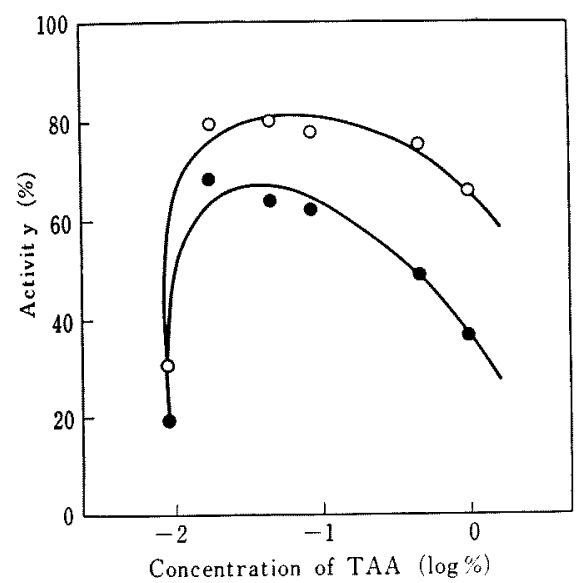

FIG. 4. Effect of Initial Concentration of TAA on the Reactivation.

Samples of TAA in various initial concentrations were acidified to $\mathrm{pH} 1.0$, kept for $10 \mathrm{~min}$. They

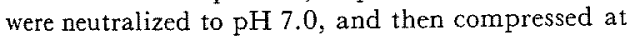
$1500 \mathrm{~kg} / \mathrm{cm}^{2}$ for $60 \mathrm{~min}$. Activities were measured after $2 \mathrm{hr}(\mathrm{O}-\mathrm{O})$. (-) indicates those obtained under atmospheric pressure. Temperature: $30^{\circ} \mathrm{C}$. were optimum for the reactivation and the higher the concentration, the greater the effect of pressure.

From the above results, the pressure effect on the reactivation of acid-denatured and then neutralized TAA may be explained as follows; roughly speaking, the first step of denaturation is the destruction of the structure itself and the association or the coagulation of the denatured-protein follows. If the coagurated or the associated protein can be disaggregated by some means, the higher structure destroyed will be spontanously regained to the native state under an appropriate condition. That is, the higher structure of protein is governed by the primary structure. Our present results show that some bonds of protein-protein interaction (association or coagulation) might be broken by a moderate pressure (see Figs. 1 and 3), and pressure does not affect on the reconstruction of the structure (in this process, the reactivation should be appeared) (see Fig. 3). Therefore, as shown in Fig. 4, at lower concentrations of TAA, the pressure effect is small, but at higher concentrations, proteinprotein interaction may easily occur when TAA is denatured by an acid. Pressure should break the interacted bonds, so that the pressure effect is greater.

The authors wish to express their gratitued to Sankyo Co., Ltd. for a supply of Taka-diastase Sankyo. 